\title{
UMA ANÁLISE DA TRANSMISSÃO DA POLÍTICA MONETÁRIA E O CANAL DA DÍVIDA PÚBLICA COM APLICAÇÃO AOS DADOS BRASILEIROS
}

\author{
Manoel Carlos de Castro Pires \\ Joaquim Pinto de Andrade ${ }^{\dagger}$
}

\begin{abstract}
Resumo
Este artigo tem por objetivo analisar o papel da dívida pública no mecanismo de transmissão monetária enfatizando o efeito riqueza como potencial fonte de ineficácia da política monetária. O modelo elaborado consiste em uma curva IS na qual não prevalece a Equivalência Ricardiana e em uma curva de Phillips estimadas por FIML, GMM e Bootstrap. A restrição orçamentária do governo permite a análise de dois tipos de títulos: (i) prefixados e (ii) indexados pela taxa de juros de política monetária. Para concluir o modelo, estipula-se uma regra monetária compatível com Taylor (1993) e uma regra fiscal. As funções de impulso resposta indicam que os ciclos dependem da composição da dívida pública.
\end{abstract}

Palavras-chave: Composição da Dívida, Regra Monetária, Regra Fiscal

\begin{abstract}
This paper deals with the role of the public debt on the transmission mechanism of monetary policy in order to evaluate the wealth effect as a source of monetary policy ineffectiveness. An IS function where the Ricardian Equivalence does not prevail and Phillips curve are estimated by FIML, GMM and Bootstrap methods. The government constraint allows the analysis of two kinds of bonds: prefixed bonds and bonds indexed by monetary policy interest rate. Two additional relations are added to the model, one monetary rule and one fiscal rule. The impulse response functions present cycles that depend heavily on the composition of the public debt.
\end{abstract}

Keywords: Debt Composition, Monetary Rule, Fiscal Rule

JEL classification: C5, E4, E5

\footnotetext{
* Técnico de Pesquisa e Planejamento do IPEA. Contato: manoel.pires@ipea.gov.br.

† Professor do Departamento de Economia da UnB. Contato: jandrade@unb.br.
} 


\section{Introdução}

A importância da política fiscal e a sua combinação com a política monetária na administração da demanda agregada e no combate à inflação sempre estiveram no centro do debate macroeconômico. Tobin (1963) argumenta que a gestão da dívida pública é um fator importante na administração da demanda agregada, pois ela altera o tamanho e a composição da riqueza privada. ${ }^{1} \mathrm{Em}$ um artigo famoso, Sargent e Wallace (1981) mostram que a política monetária pode ser completamente ineficaz no combate à inflação, caso a política fiscal não seja sustentável. Com efeito, se a política monetária for restritiva e a política fiscal deficitária, a política monetária terá que acomodar a política fiscal para obedecer à restrição orçamentária do governo na ausência de um ajuste fiscal. Esse resultado corrobora a interpretação de Sargent (1981) sobre o processo hiperinflacionário em países que passaram por esse tipo de problema. Segundo o autor, a hiperinflação observada nesses países foi resultado de um processo fiscal desequilibrado o que exigia que o banco central desses países fosse obrigado a emitir moeda com o intuito de financiar o governo. Esse debate culminou com a idéia de que a inflação era determinada pela política fiscal, o que ficou conhecido como teoria fiscal do nível de preços. ${ }^{2}$

Os desenvolvimentos de Blinder $(1982)^{3}$ definiram as bases para uma modelagem Keynesiana que relacionasse as principais interações entre a política fiscal e monetária. ${ }^{4}$ Nordhaus (1994) incorporou essas bases em um modelo que discutiu a interação entre as políticas monetária e fiscal em uma linguagem de teoria dos jogos.

A interação entre a política fiscal e monetária é central para a análise macroeconômica no Brasil. O ex-presidente do Banco Central do Brasil reconheceu que o sucesso do regime de metas de inflação pressupõe a ausência de dominância fiscal (Fraga et al. 2003). Além dos mecanismos tradicionais de política fiscal como a dívida pública e o déficit primário, o fato de parcela da dívida pública no Brasil estar indexada à taxa de juros de curto prazo traz uma peculiaridade não considerada nos modelos mais tradicionais.

O objetivo desse artigo é analisar o mecanismo de transmissão da política monetária com ênfase no papel da dívida pública e na sua composição caracterizando o efeito portfólio que mede como a composição da dívida pública afeta a demanda agregada e, consequentemente, a política monetária (Loyo 2006). Com efeito, esse artigo contém cinco seções além dessa introdução. A próxima seção discute de forma não exaustiva, a gestão da dívida pública no Brasil com foco na sua composição, apresentando as principais implicações para a política monetária e argumentando principalmente que a composição da dívida pública deve ser considerada na aplicação desses modelos. A terceira seção apresenta as principais características que um modelo de curto prazo deve possuir para analisar a interação entre as políticas fiscal e monetária.

\footnotetext{
${ }^{1}$ Para uma análise clássica sobre como a gestão da dívida pública pode ser administrada com objetivos de afetar a demanda agregada, ver Modigliani e Sutch (1966) que analisou a os efeitos da gestão da dívida pública sobre a demanda agregada na administração Kennedy.

${ }^{2}$ Ver Woodford (1997).

${ }^{3}$ De acordo com Blinder (1982), a questão da coordenação entre a política monetária e fiscal consiste na escolha da combinação entre o déficit e a taxa de juros, o chamado policy mix.

${ }^{4}$ Para uma análise das principais diferenças entre a análise monetarista e a teoria fiscal do nível de preços, ver McCallum e Nelson (2007).
} 
A quarta seção propõe um modelo de curto prazo que se preocupa explicitamente com o papel da dívida pública na transmissão da política monetária e fiscal. Em outras palavras, o modelo tem por objetivo dar conta de alguns dos impactos macroeconômicos da dívida pública. Em seguida, o modelo foi estimado para avaliar sua adequação na descrição do ciclo econômico. Na quinta seção, o modelo é avaliado a partir de funções de impulso resposta. Em seguida, seguem algumas conclusões do artigo.

\section{Considerações sobre a Política Fiscal Brasileira}

No início dos anos 1990, Guidotti \& Kumer (1991) sugeriram que o problema de gestão da dívida pública, em países como o Brasil, que não conseguiam se financiar com títulos prefixados e de longo prazo, era composto por dois fatores: a elevada taxa de inflação e o elevado déficit público. Com o início do Plano Real, em junho de 1994, imaginou-se que a gestão da dívida pública seria facilitada com a possibilidade de colocação de títulos prefixados ainda que de prazo curto. ${ }^{5}$ De fato, a participação de títulos prefixados aumentou gradativamente.

Contudo, com os choques internacionais (na Ásia em 1997, na Rússia em 1998 e no Brasil no início de 1999) o esforço efetuado pelo Tesouro Nacional no sentido de ampliar a participação dos títulos prefixados recrudesceu, pois o prazo dos títulos continuou muito curto, de forma que o risco de refinanciamento para o Tesouro continuava alto e a taxa de juros exigida em momentos de turbulência foi considerada muito elevada, o que fazia com que o Tesouro Nacional recuasse nesse processo. De fato, a parcela da dívida pública com títulos prefixados em 1998 pode ser considerada desprezível. A Tabela 1 apresenta a evolução da composição da dívida mobiliária federal brasileira.

Em 1998, o Brasil ajustou seu déficit primário tornando-o equilibrado por conta da crise russa. A partir de 1999 o governo implementou um programa de metas crescentes de superávit primário que culminou com o valor de $4,25 \%$ do PIB no período 2003-6, além de ter introduzido no campo da política monetária o regime de metas para a inflação em 1999. Apesar desse arcabouço, em termos de gestão da dívida pública, pouco mudou. Ainda que a participação dos títulos prefixados tenha aumentado, os títulos pós-fixados correspondem a quase $50 \%$ da dívida pública. O Tesouro Nacional tem usado principalmente três instrumentos de indexação da dívida pública: (i) a taxa de câmbio, (ii) a taxa de inflação e; (iii) a taxa de juros de curto prazo (Selic), principal instrumento de política monetária. ${ }^{6}$

\footnotetext{
${ }^{5} \mathrm{~A}$ inflação é o maior problema para a colocação de títulos prefixados, pois gera incerteza em relação ao rendimento do título, de forma que os demandantes exigem alguma forma de indexação. O déficit público dificulta a colocação de títulos de longo prazo na medida em que gera incerteza quanto o pagamento do mesmo no futuro. O déficit público também gera incerteza em relação à trajetória futura da inflação, conforme Sargent (1981).

${ }^{6} \mathrm{~A}$ parcela da dívida indexada à taxa de câmbio ou à taxa de inflação pode ser pensada como um título com rendimento real prefixado, principalmente se o câmbio se comportar de acordo com a teoria da paridade do poder de compra e a inflação internacional for próxima de zero. Essa interpretação é apenas uma simplificação, pois na freqüência do ciclo de negócios, a taxa de câmbio não se comporta conforme a teoria da paridade do poder de compra. Nesse sentido, essa pesquisa representa também uma plataforma para trabalhos futuros com a introdução do setor externo cumprindo um papel importante. Agradecemos a um referee anônimo por esse comentário. Para os propósitos desse artigo, a discussão se centrará no papel dos títulos indexados à taxa de juros de curto prazo e no seu impacto sobre a eficácia da política monetária.
} 
Tabela 1: Participação por indexador de dívida pública

\begin{tabular}{cccccc}
\hline & Câmbio & inflação & Selic & prefixado & outros \\
\hline 1996 & 9,4 & 1,8 & 18,6 & 61,0 & 9,2 \\
1997 & 15,4 & 0,3 & 34,8 & 40,9 & 8,6 \\
1998 & 21 & 0,4 & 69,1 & 3,5 & 6,0 \\
1999 & 24,2 & 2,4 & 61,1 & 9,2 & 3,1 \\
2000 & 22,5 & 6,0 & 52,7 & 14,9 & 3,9 \\
2001 & 29,5 & 7,2 & 54,4 & 8,1 & 0,8 \\
2002 & 20,3 & 11,4 & 55,2 & 2,0 & 11,1 \\
2003 & 10,0 & 12,6 & 57,0 & 11,6 & 8,8 \\
2004 & 4,9 & 14,1 & 54,0 & 19,0 & 8,0 \\
2005 & 2,6 & 15,2 & 50,6 & 27,2 & 4,4 \\
2006 & 0,0 & 21,4 & 42,6 & 24,8 & 11,26 \\
\hline
\end{tabular}

Fonte: Boletim do Banco Central do Brasil, vários números.

Passado os efeitos da crise eleitoral de 2002, que elevou a taxa de câmbio nominal de 2,36 R\$/US\$ para 3,89 R \$/US\$ em apenas cinco meses, a parcela da dívida pública indexada à taxa de câmbio foi reduzida até se tornar inexpressiva. Em um primeiro momento, a parcela da dívida indexada à taxa de juros de curto prazo aumentou e, em seguida, aumentou a parcela indexada à taxa de inflação e, finalmente, os títulos prefixados. Entretanto, a taxa exigida pelos títulos prefixados é muito elevada de forma que em muitas ocasiões o Tesouro Nacional se recusa a emitir tais títulos. Em suma, é possível que essa transição seja muito lenta de forma que os impactos macroeconômicos de tal composição devem ser levados em conta na análise da coordenação entre a política monetária e fiscal.

A importância da gestão da dívida pública é crucial na discussão da eficácia da política monetária no Brasil. ${ }^{7}$ De acordo com Pastore (1995), em um contexto de restrição de liquidez, a parcela da dívida pública atrelada à taxa Selic (conhecida como LFT's) gera efeito renda. Quando a taxa de juros se eleva, os fluxos de rendimentos dos detentores dos títulos aumentam, elevando a renda disponível o que pode gerar um efeito positivo no consumo, estimulando a demanda agregada. A percepção de que a política monetária no Brasil perde eficácia é recorrente em artigos sobre o tema. ${ }^{8}$

A ineficácia da política monetária no Brasil é um tema crucial para o entendimento dos mecanismos de transmissão da mesma e um tema recorrente no debate brasileiro diante dos patamares observados no nível da taxa de juros Selic no período pós-Real. A taxa de juros real média no período de 19951998 , um período de turbulência internacional, foi próxima de $20 \%$. No período de 1999-2006, a taxa de juros real média situou-se perto de 11\%. Ambas as médias são muito elevadas se comparadas com as taxas praticadas por ou-

\footnotetext{
${ }^{7}$ Esse artigo não tem por objetivo exaurir o tema da administração da dívida pública brasileira. Para uma análise aprofundada, ver Bevilaqua e Garcia (2002).

${ }^{8}$ Os próprios economistas do Banco Central do Brasil reconhecem a importância desse fenômeno (Bevilaqua et al. 2007). De todo o modo, é claro que esse efeito não tira toda a eficácia da política monetária. Existem outros canais que garantem sua eficácia, como, por exemplo, seu efeito sobre a taxa de câmbio e o efeito sobre o patrimônio das firmas. Para mais detalhes, ver Bevilaqua et al. (2007). Ademais, Loyo (2006) questiona a relevância do efeito riqueza no canal de transmissão da política monetária por conta da elevada desigualdade de renda no Brasil e por conta da equivalência ricardiana.
} 
tros países emergentes. Com efeito, uma análise que considera o efeito da gestão da dívida pública como um canal de transmissão da política monetária pode render alguns insights importantes sobre este fenômeno.

\section{Alguns Princípios para Modelar a Coordenação entre as Políticas Monetária e Fiscal}

Quais devem ser os princípios para uma análise que incorpore os principais aspectos da relação entre a política monetária e a política fiscal? Analisando a literatura gerada sobre o tema, pode-se chegar a três princípios. O primeiro princípio deve considerar os impactos da política fiscal em um modelo macroeconômico tal como o novo keynesiano.Muscatelli et al. (2004) modelam uma curva IS que é afetada pelo nível de gastos do governo.Lambertini \& Rovelli (2003) também utilizam a curva IS como canal de transmissão da política fiscal usando, entretanto, o déficit primário como medida de política.Nordhaus (1994), da mesma forma, usa o déficit primário na curva IS como canal de transmissão da política fiscal.Kirsanova et al. (2005) analisam a curva IS com a dívida pública.Bénassy (2007) também modela a dívida pública na curva IS. $^{9}$

O segundo princípio deve se preocupar em como modelar explicitamente a política fiscal. Duas formam emergem na literatura. Na primeira forma, Muscatelli et al. (2004) modelam a política fiscal (gastos primários e receitas) de forma autoregressiva sem considerar a dívida pública. Na segunda forma, Nordhaus (1994) e Lambertini e Lambertini \& Rovelli (2003) consideram o déficit primário determinado de forma endógena em um modelo estático, criando uma regra fiscal. As duas opções, por motivos diferentes, têm o mesmo custo: a política fiscal não se preocupa com a trajetória da dívida pública.

No primeiro caso, os gastos primários e as receitas são exógenos e, por isso, o superávit primário não tem uma relação estável com a dívida pública. No segundo caso, o problema foi bem explicitado por Tobin (1980) quando o autor argumenta que a principal falha do modelo Keynesiano foi não considerar a restrição orçamentária do governo na análise da política fiscal de forma que os impactos macroeconômicos de sucessivos déficits foram subestimados. Em outras palavras, Tobin (1980) argumenta que esses modelos devem ser dinâmicos e não estáticos. A sugestão deFavero (2004) é que a política fiscal deve ser modelada por meio da sua restrição orçamentária.Kirsanova et al. (2005) eBénassy (2007) explicitam a dinâmica da dívida pública como parte do modelo.

O terceiro princípio se refere à forma como modelar as interações entre as políticas monetária e fiscal, ou seja, como se comportam as instituições responsáveis pela definição das políticas. Leeper (1991), por exemplo, define regras de política para a análise de equilíbrio do seu modelo. Seu principal

\footnotetext{
${ }^{9}$ As evidências empíricas sobre a transmissão da política fiscal, por meio de vetores autoregressivos, não podem ser consideradas conclusivas. O debate metodológico, nesse caso, está centrado em torno da identificação do VAR.Perrot (2007) encontra evidências de efeitos keynesianos para a política fiscal, confirmando os resultados encontrados por Blanchard \& Perrot (2002). Ramey \& Shapiro (1998) encontram evidências de que os gastos públicos estimulam investimento e reduzem consumo. Esse resultado é exatamente oposto ao reportado por Mountford \& Uhlig (2002) que concluem que a melhor política fiscal para estimular a economia é a elevação do déficit por meio de cortes nos impostos. Para o caso do Brasil, verPeres (2007).
} 
resultado é que para existir equilíbrio basta que uma política seja ativa e a outra seja passiva. ${ }^{10}$

Uma boa contribuição a essa questão foi elaborada por Blinder (1982) que vê a interação entre as políticas como um jogo entre as instituições. Lambertini \& Rovelli (2003) adotam esse enfoque e modelam a interação entre as políticas como um modelo de Nash (solução simultânea não cooperativa) em que as duas instituições determinam suas políticas sem considerar o que a outra está fazendo e em um modelo Stackelberg (solução não simultânea) no qual existe uma instituição líder e uma outra que se comporta como seguidora. $\mathrm{Na}$ prática, isso significa que a líder incorpora a regra ótima da seguidora, mas o contrário não ocorre. Seus resultados indicam que a solução não simultânea é preferida e que a política fiscal deve ser a líder. A intuição para esse resultado é que a política fiscal é revisada menos frequentemente.Benigno \& Woodford (2006) seguem um enfoque semelhante, entretanto, é o banco central que determina a política monetária ótima sendo constrangido pela restrição orçamentária do governo, ou seja, no contexto Benigno \& Woodford (2006) a política monetária é a líder. ${ }^{11}$

O arcabouço de análise apresentado nesse artigo possui duas características que o distinguem da literatura citada acima. Em primeiro lugar, conforme Kirsanova et al. (2005), o modelo a ser analisado se preocupa em avaliar o mecanismo de transmissão da política fiscal onde a dívida pública é o principal canal de transmissão no sentido de que significa variação de riqueza dos agentes. ${ }^{12}$ Em segundo lugar, a política fiscal é modelada por meio de sua restrição orçamentária para dar conta das questões dinâmicas envolvidas e incorpora, ainda, a questão da composição da dívida indexada à taxa de juros de curto prazo.

\section{Um Modelo de Curto Prazo com Aplicações para o Brasil}

O modelo discutido nesse artigo apresenta as principais características necessárias para analisar a interação entre a política fiscal e monetária: (i) modela explicitamente na curva IS a transmissão da política fiscal via dívida pública, (ii) a restrição orçamentária do governo é considerada para análise da consistência intertemporal da política fiscal e; (iii) a administração da dívida pública é especificada, permitindo a existência de dois títulos: um indexado à taxa de juros instrumento de política monetária e o outro prefixado.

Algumas hipóteses devem ser explicitadas. O déficit público pode ser financiado por dois títulos públicos: (i) prefixado e (ii) indexado à taxa de juros de curto prazo. O modelo não considera capital e gastos do governo. Assim como em Bénassy (2007) a política fiscal pode ser pensada como uma política de subsídios e os déficits fiscais são gerados por uma política de subsídios positivos aos agentes. O banco central controla a taxa de juros real, fixando a taxa de juros nominal com a identidade de Fisher, assegurando essa equivalência.

\footnotetext{
${ }^{10}$ Política ativa significa uma política com coeficiente de resposta maior que um e política passiva significa uma política com coeficiente menor que um.

${ }^{11} \mathrm{O}$ mesmo enfoque foi adotado por Muscatelli et al. (2004). Note que, como os autores modelam a política fiscal de forma exógena, foi natural adotar essa solução.

${ }^{12}$ Naturalmente, assume-se que os títulos públicos constituem riqueza líquida diferentemente deBarro (1974).
} 
A curva IS proposta tem sido derivada de duas formas na literatura. Blanchard (1985) mostra, por exemplo, que em modelos nos quais os agentes possuem uma probabilidade positiva de morte, a expectativa de dívida pública afeta positivamente o consumo dos agentes, pois representa variação na riqueza privada. Essa é a modelagem utilizada em Kirsanova et al. (2005).

Bénassy (2007) deriva uma curva IS em que a expectativa de dívida pública também afeta positivamente o consumo dos agentes, entretanto, em um contexto cash in advance. A curva IS proposta neste artigo, portanto, modela a dívida pública esperada impactando positivamente a demanda agregada.

A curva IS híbrida proposta é dada por:

$$
\hat{c}_{t}=\rho E_{t} \hat{c}_{t+1}+\mu \hat{r}_{t-1}+\alpha E_{t} \hat{b}_{t+1}+\varepsilon_{A D, t}
$$

De acordo com (1), a curva IS híbrida define o consumo (ct) como função do consumo esperado $(E t)$ no período seguinte, da taxa de juros real $(r t-1)$ e da dívida pública esperada no período seguinte $(b t+1)$. Permite-se, ainda, a existência de choques de demanda $(\epsilon A D, t)$ que podem ser devidos a mudanças nas preferências dos consumidores. As variáveis com "chapéu" denotam desvio do steady state em logaritmo.

A oferta agregada (curva de Phillips) é definida como:

$$
\pi_{t}=\chi E_{t} \pi_{t+1}+(1-\chi) \pi_{t-1}+\lambda \hat{c}_{t}+\varepsilon_{A S, t}
$$

A curva de Phillips novo keynesiana com indexação define a taxa de inflação no período $t\left(\pi_{t}\right)$ como uma média ponderada da inflação futura e da inflação passada e também da demanda agregada. A curva de Phillips tal como definida acima foi microfundamentada em Woodford (2003). Permitese, ainda, a existência de choques de oferta $(\epsilon A S, t)$.

A dinâmica da dívida pública nominal é dada pela restrição orçamentária, em que $\phi$ é a parcela da dívida indexada à taxa de juros nominal de curto prazo $(i t)$ e $(1-\phi)$ é a parcela prefixada da dívida que paga uma taxa nominal prefixada $R^{\star}$. O termo $(D t)$ corresponde ao déficit primário (que desconsidera as despesas financeiras), e os impostos são considerados não distorcivos (ou lump sum): ${ }^{13}$

$$
B_{t}=D_{t}+\phi\left(1+i_{t}\right) B_{t-1}+(1-\phi)\left(1+R^{*}\right) B_{t-1}
$$

Para escrever a restrição do governo em termos reais (onde $x_{t}=\frac{X_{t}}{P_{t}}$ ), basta dividir pelo nível de preços $(P t)$ para obter ${ }^{14}$ :

$$
b_{t}=d_{t}+\phi\left(1+r_{t}\right) b_{t-1}+(1-\phi) \frac{\left(1+R^{*}\right)}{\left(1+\pi_{t}\right)} b_{t-1}
$$

A loglinearização da equação $(4)$ rende: ${ }^{15}$

$$
\hat{b}_{t}=\psi_{0} \hat{d}_{t}+\phi \psi_{1} \hat{r}_{t}-(1-\phi) \psi_{2} \hat{\pi}_{t}+\psi_{3} \hat{b}_{t-1}+\varepsilon_{b, t}
$$

A equação de dinâmica da dívida pública indica que o déficit primário contribui positivamente para o seu acréscimo, assim como a taxa de juros real

\footnotetext{
${ }^{13} \mathrm{Na}$ verdade, basta assumir que o governo faz um volume de transferências ao setor privado tal que elimine os efeitos distorcivos da política tributária, ver Calvo (1983).

${ }^{14}$ Admite-se a equação de Fisher $(1+i t)=(1+r t)\left(1+\pi_{t}\right)$ para a derivação da equação (4).

${ }^{15}$ A derivação desta equação encontra-se no apêndice A.
} 
de curto prazo e o estoque da dívida. De forma alternativa, a inflação contribui com sinal negativo para a dinâmica da dívida pública. Um fator relevante para a dinâmica da dívida pública é a sua composição. Com efeito, quanto mais elevada for a participação dos títulos indexados à taxa de juros de curto prazo (maior $\phi)$, maior a contribuição da política monetária na dinâmica da dívida e menor a participação direta da inflação.

O modelo é fechado com uma equação que determina o comportamento da política monetária (regra para a taxa de juros) e da política fiscal (regra para o déficit público). Nas próximas duas subseções, o modelo apresentado (equações 1 e 2) é estimado com o objetivo da avaliar se o mesmo descreve bem o ciclo econômico no Brasil.

Vale ressaltar que o mecanismo de transmissão modelado é uma versão ampliada do efeito riqueza. O mecanismo de transmissão pode ser caracterizado como um efeito portfólio que decorre da mudança na composição da dívida pública em favor de títulos prefixados que carregam risco de juros e de inflação. O efeito portfólio reflete a noção de que mudanças na duração da dívida possuem impactos sobre o equilíbrio macroeconômico (Loyo 2006). ${ }^{16}$

O canal de transmissão proposto na análise, portanto, consiste em avaliar como a alteração na parcela da dívida indexada à taxa de juros de curto prazo afeta a eficácia das políticas econômicas. A composição da dívida afeta a demanda agregada de duas formas: (i) a elevação dos juros aumenta as transferências para o setor privado o que induz a demanda positivamente e, (ii) a elevação da inflação tem efeitos corrosivos sobre o rendimento real dos títulos prefixados o que reduz a demanda agregada caracterizando o efeito renda e uma forma simplificada para o efeito riqueza, respectivamente. ${ }^{17}$ Ambos os efeitos, ou dito de outra forma, manipulações na composição da dívida caracterizam o efeito portfólio.

\subsection{A Base de Dados e Testes de Raiz Unitária}

A base de dados consiste de dados trimestrais que cobrem o período 1996:1 a 2007:2. A série de consumo foi obtida nas contas nacionais trimestrais do IBGE, índice de volume "referência 2000". A série de dívida pública mensal (dívida líquida nominal do setor público) do Banco Central do Brasil foi trimestralizada a partir da média dos meses que correspondem ao trimestre e deflacionada pelo deflator trimestral do PIB de forma a constituir um índice de volume. A inflação trimestral foi calculada a partir do IPCA - variação percentual trimestral do número índice. Calculou-se uma série de número índice trimestral e a taxa de inflação foi definida como $\ln (P t)-\ln (P t-1)$ onde ln corresponde ao logaritmo natural.

A taxa de juros Selicé divulgada pelo Banco Central com freqüência mensal. Ela foi trimestralizada a partir da média aritmética do trimestre e deflacionada pela taxa de inflação descrita acima do mesmo trimestre, constituindose em uma taxa de juros real ex-post. Ademais, aplicou-se a função logaritmo natural à série de taxa de juros real.

As séries consumo, dívida pública e juros real ex post foram filtradas com o filtro HP para que o valor possa ser utilizado como referência para o steady

\footnotetext{
${ }^{16}$ Para uma análise clássica do efeito portfólio, verModigliani \& Sutch (1966).

${ }^{17} \mathrm{O}$ efeito riqueza analisado, nesse modelo, se aproxima do sentido original do termo conhecido como efeito Pigou, onde variações do nível de preços modificam o valor real dos ativos afetando assim a demanda agregada.
} 
Tabela 2: Teste ADF de raiz unitária

\begin{tabular}{cccc}
\hline Variáveis & Modelo & Estatística $t$ & Probabilidade \\
\hline$\hat{c}$ & c/ constante, 0 lags & $-3,3523$ & 0,0182 \\
$\hat{b}$ & c/ constante, 0 lags & $-3,0149$ & 0,0410 \\
$\pi$ & c/ constante, 0 lags & $-4,2633$ & 0,0015 \\
$\hat{r}$ & c/ constante, 0 lags & $-4,2452$ & 0,0016 \\
\hline
\end{tabular}

state. É importante notar que, diferentemente da maior parte das aplicações onde se utiliza a média do período como valor de referência de steady state, optou-se pelo uso da série filtrada para essa referência. Isso se justifica porque o período coberto observou choques de elevada magnitude como as crises financeiras internacionais nos anos 1990 e as crises energética (em 2001) e eleitoral (em 2002) de forma que a aplicação dessa forma pode amenizar a presença de observações aberrantes bem como contemplar possíveis alterações nos próprios valores de equilíbrio das variáveis envolvidas no período. ${ }^{18}$

Para que os procedimentos de estimação tradicionais possam ser efetuados é necessário estudar as características das séries como a ordem de integração e a possibilidade de quebras estruturais. Em relação à demanda agregada, pode-se notar a presença de dois choques "aberrantes": o primeiro positivo em 1996-4 e o segundo negativo em 2003-2/3. Esses dois choques podem dar a impressão de que a série se comporta como um passeio aleatório quando, de fato, é estacionária. O mesmo comentário se aplica à série de dívida que em 1999-1 sofreu um choque significativo.

As séries de juros e inflação apresentam choques (em 1999-1 e 2003-1 para a primeira e em 2003-2 para a segunda), mas que não parecem afetar as características estatísticas das variáveis. Com efeito, nesses dois casos é comum observar reversão para a média. Com o intuito de avaliar essa percepção inicial, foram aplicados testes de raiz unitária.

A análise dos resultados do teste de raiz unitária mostra que as variáveis podem ser consideradas estacionárias. O teste ADF (Tabela 2) rejeitou a hipótese nula de raiz unitária em todas as variáveis indicando que a observação dos choques não afetou os resultados sugeridos pela inspeção gráfica das mesmas. Apenas para corroborar esses resultados, aplicou-se o teste Saikkonen \& Lutkepohl (2002) (SL) de raiz unitária que modela explicitamente a quebra estrutural (Tabela 3). Ao modelar a quebra estrutural como uma dummy de impulso, o teste rejeita para todas as variáveis a hipótese nula de raiz unitária.

\subsection{Resultados das Estimativas}

O procedimento de estimação foi realizado de duas formas: (i) por OLS equação por equação e, (ii) por full information maximum likelihood (FIML) (Tabela 4). Conforme notam Cho \& Moreno (2006) a estimação por FIML resulta em significativo ganho de desempenho, pois permite aproveitar a informação entre o setor público (Banco Central e Tesouro Nacional) e o setor privado. Com efeito, o parâmetro que mede o efeito do hiato do produto sobre a inflação não é significativo e possui sinal invertido na estimação por OLS. Na estimação por FIML, o mesmo parâmetro é significativo e com o sinal esperado. Os demais parâmetros possuem o sinal correto e são todos significativos.

\footnotetext{
${ }^{18} \mathrm{~A}$ evolução das séries encontra-se no apêndice B.
} 
Tabela 3: Teste $S L$ de raiz unitária com quebra estrutural.

\begin{tabular}{ccccc}
\hline Variáveis & $\begin{array}{c}\text { Modelo (dummy } \\
\text { impulso) }\end{array}$ & Quebra & $\begin{array}{c}\text { Estatística } \\
\text { de teste }\end{array}$ & $\begin{array}{c}\text { Valor } \\
\text { Crítico 5\% }\end{array}$ \\
\hline$\hat{c}$ & $\mathrm{c} /$ constante, 2 & $2001-2$ & $-3,4427$ & $-2,88$ \\
$\hat{b}$ & $\begin{array}{c}\text { lags } \\
\text { c/ constante, 2 } \\
\text { lags }\end{array}$ & $1998-2$ & $-3,1224$ & $-2,88$ \\
$\pi$ & $\mathrm{c} /$ constante, 2 & $2003-1$ & $-2,9681$ & $-2,88$ \\
$\hat{r}$ & $\begin{array}{c}\text { lags } \\
\text { c/ constante, 2 } \\
\text { lags }\end{array}$ & $2002-4$ & $-2,8798$ & $-2,88$ \\
\hline
\end{tabular}

Uma possível explicação para esse fenômeno é que em momentos de choques de oferta, o consequente aumento da inflação reduz a dívida pública e eleva a taxa de juros o que reduz a demanda agregada e, portanto, impõe uma correlação negativa entre as variáveis. A estimação por modelos de equações simultâneas tende a corrigir esse fenômeno.

Em relação à estabilidade dos parâmetros estimados, pode-se notar que os testes CUSUM e de coeficientes recursivos não demonstram evidência de instabilidade. Ademais, na estimação OLS equação por equação a curva IS não apresenta evidência de não normalidade dos resíduos (pelo teste Jarque-Bera) nem de correlação serial (correlograma). Ainda na estimação OLS, a curva de Phillips apresenta evidência de correlação serial no correlograma de forma que o erro-padrão foi estimado por Newey-West para corrigir os problemas derivados da autocorrelação.

Os parâmetros estimados indicam que a dívida pública possui efeito significativo sobre o consumo. Os demais parâmetros, com exceção da taxa de juros, possuem magnitude similar da reportada por Cho \& Moreno (2006), ainda que os autores não encontrem significância do hiato do produto na curva de Phillips em algumas das especificações. ${ }^{19}$

Substituindo consumo $(c t)$ pela renda $(y t)$, o modelo pode ser escrito como:

$$
\begin{gathered}
\text { haty }_{t}=0,524 \hat{y}_{t+1}-0,025 \hat{r}_{t-1}+0,128 E_{t} \hat{b}_{t+1}+\varepsilon_{A D, t} \\
\pi_{t}=0,478 \pi_{t+1}+0,522 \pi_{t-1}+0,260 \hat{y}_{t}+\varepsilon_{A S, t}
\end{gathered}
$$

As estimativas reportadas na Tabela 4, obtidas por OLS e FIML, assumem a hipótese de previsão perfeita, pois as expectativas condicionais são iguais às variáveis observadas. Ao relaxar essa hipótese, o modelo não mais pode ser estimado por nenhum destes métodos. Com efeito, na ausência da hipótese de previsão perfeita, tem-se que a substituição das expectativas condicionais das variáveis pelas próprias variáveis observadas causa uma modificação no modelo que torna os erros serialmente correlacionados:

\footnotetext{
${ }^{19}$ No caso da taxa de juros, a diferença pode resultar de dois fatores. Em primeiro lugar, o artigo dos autores usa o PIB e não o consumo de forma que uma parte significativa da variável usada pelos mesmos não responde diretamente à taxa de juros (como os gastos do governo). Em segundo lugar, existe uma ligeira diferença na curva IS dos autores que usam a taxa real de juros apenas e não o desvio além do fato que a taxa de juros está em logaritmo.
} 
Tabela 4: Estimativas dos parâmetros do modelo: OLS e FIML

\begin{tabular}{|c|c|c|c|c|c|c|}
\hline & \multicolumn{3}{|c|}{ OLS - Equação por equação } & \multicolumn{3}{|c|}{ FIML } \\
\hline & Coeficiente & $\begin{array}{c}\text { Erro } \\
\text { Padrão }\end{array}$ & Prob. & Coeficiente & $\begin{array}{l}\text { Erro } \\
\text { Padrão }\end{array}$ & Prob. \\
\hline$\rho$ & 0,690 & 0,102 & 0,000 & 0,524 & 0,114 & 0,000 \\
\hline$\mu$ & $-0,014$ & 0,006 & 0,012 & $-0,025$ & 0,007 & 0,000 \\
\hline$\alpha$ & 0,127 & 0,055 & 0,026 & 0,128 & 0,053 & 0,018 \\
\hline$\chi$ & 0,492 & 0,085 & 0,000 & 0,478 & 0,075 & 0,000 \\
\hline$\lambda$ & $-0,016$ & 0,096 & 0,861 & 0,260 & 0,139 & 0,062 \\
\hline
\end{tabular}

$$
\hat{y}_{t}=\rho \hat{y}_{t+1}+\mu \hat{r}_{t-1}+\alpha \hat{b}_{t+1}+v_{A D, t}
$$

onde $v_{A D, t}=\rho\left(E_{t} \hat{y}_{t+1}-\hat{y}_{t+1}\right)+\alpha\left(E_{t} \hat{b}_{t+1}-\hat{b}_{t+1}\right)+\varepsilon_{A D, t}$.

$$
\pi_{t}=\chi \pi_{t+1}+(1-\chi) \pi_{t-1}+\lambda \hat{y}_{t}+v_{A S, t}
$$

onde $v_{A S, t}=\chi\left(E_{t} \pi_{t+1}-\pi_{t+1}\right)+\varepsilon_{A S, t}$.

Assim, a forma correta de estimar o modelo, na ausência de previsão perfeita, é por meio do Método Geral de Momentos (GMM). ${ }^{20}$

Para estimar o modelo por meio do GMM é importante definir a lista de instrumentos a ser utilizada. A Tabela 5 apresenta duas estimações para o GMM. A primeira estimação (GMM 1) usa as defasagens 3, 4 e 5 da taxa de inflação, do consumo, da dívida e da taxa de juros. A segunda estimação (GMM 2) usa a lista de instrumentos anterior e as defasagens 3, 4 e 5 do índice de preços das commodities.

Os resultados indicam que a hipótese de previsibilidade perfeita não produz alteração significativa nos resultados. Na primeira estimativa (GMM 1), apenas o parâmetro que mede o efeito da dívida pública sobre a demanda agregada não é significativo. Na segunda estimativa (GMM 2), todos os parâmetros são significativos e com o sinal adequado. Do ponto de vista qualitativo, ressalta-se que o parâmetro que mede o efeito da demanda agregada futura sobre a demanda agregada $(\rho)$ é bem maior nas estimativas obtidas pelos GMM 1 e 2 que nas estimativas anteriores.

É importante ressaltar que a diferença entre as duas estimativas está na inclusão do índice de preços das commodities na lista de instrumentos. Assim, a inclusão dessa variável parece ser importante para produzir resultados semelhantes aos obtidos pelo FIML. Com a variação dos resultados obtidos em virtude de diferentes instrumentos, é importante analisar a adequação dos mesmos e, portanto, apresenta-se a estatística $J$ que testa a validade dos instrumentos. A hipótese nula de que os instrumentos utilizados são válidos não é rejeitada em nenhum dos dois procedimentos de estimação. Assim sendo, conclui-se que os resultados obtidos por FIML podem ser considerados robustos e serão utilizados para analisar a dinâmica do modelo.

É importante ressaltar que a restrição orçamentária não precisa ser estimada porque seus parâmetros podem ser calculados a partir da observação das variáveis que os definem. Assim sendo, a Tabela 6 apresenta os valores utilizados para cálculo dos parâmetros a partir das respectivas fórmulas.

\footnotetext{
${ }^{20}$ Ver Favero (2001).
} 
Tabela 5: Estimativas dos parâmetros do modelo: GMM

\begin{tabular}{|c|c|c|c|c|c|c|}
\hline & \multicolumn{3}{|c|}{ GMM 1} & \multicolumn{3}{|c|}{ GMM 2} \\
\hline & Coefic. & $\begin{array}{c}\text { Erro } \\
\text { Padrão }\end{array}$ & Prob. & Coefic. & $\begin{array}{l}\text { Erro } \\
\text { Padrão }\end{array}$ & Prob. \\
\hline$\rho$ & 0,785 & 0,077 & 0,000 & 0,822 & 0,035 & 0,000 \\
\hline$\mu$ & $-0,019$ & 0,004 & 0,000 & $-0,009$ & 0,001 & 0,000 \\
\hline$\alpha$ & 0,032 & 0,026 & 0,230 & 0,025 & 0,014 & 0,080 \\
\hline$\chi$ & 0,557 & 0,123 & 0,000 & 0,601 & 0,054 & 0,000 \\
\hline$\lambda$ & 0,180 & 0,051 & 0,001 & 0,096 & 0,030 & 0,002 \\
\hline & \multicolumn{3}{|c|}{ Estat. $J=14,6$} & \multicolumn{2}{|c|}{ Estat. $J=15,69$} & 1) $=32,67$ \\
\hline
\end{tabular}

Uma consideração importante sobre a restrição orçamentária é que o termo de erro modelado não diz respeito a uma variável estocástica porque a mesma não foi estimada. O termo de erro representa um erro de medida por conta da aproximação. Tal erro pode ocorrer por erros de aproximação em qualquer uma das variáveis que foram aproximadas e, portanto, choques nesse termo podem representar choques de qualquer natureza. Feita esta ressalva, essa variável será interpretada como um choque fiscal. Uma intuição para esta interpretação é que no Brasil é muito importante o reconhecimento de dívidas (que são conhecidas no jargão fiscal como esqueletos) e, assim, é importante saber como erros de mensuração da dívida se transmitem pelo modelo.

De acordo com os resultados da Tabela 6, a restrição orçamentária pode ser escrita como:

$$
\hat{b}_{t}=0,0239 \hat{d}_{t}+\phi 0,0376 \hat{r}_{t}-(1-\phi) 0,0177 \hat{\pi}_{t}+1,0239 \hat{b}_{t-1}+\varepsilon_{b, t}
$$

Para concluir o modelo é preciso especificar uma regra para a política monetária e para a política fiscal. Como aproximação inicial, assume-se que a política monetária persegue a meta de inflação e que a política fiscal objetiva a suavização da demanda agregada da seguinte forma:

$$
\begin{gathered}
\hat{r}_{t}=0,5\left(\pi_{t}-\bar{\pi}\right) \\
\hat{d}_{t}=-0,5 \hat{y}_{t}
\end{gathered}
$$

O arranjo definido pelas equações (11) e (12) considera um mix de políticas onde a política monetária é ativa e a política fiscal é passiva conforme Leeper $(1991)^{21}$

\footnotetext{
${ }^{21}$ As regras de política monetária e fiscal não foram estimadas porque durante o período estudado por esse artigo existiram várias quebras estruturais. Possivelmente, uma descrição mais adequada da política fiscal seria uma regra de sustentabilidade. No período anterior ao regime de metas para a inflação, a regra monetária objetivava manter determinado nível para a taxa de câmbio. Nosso objetivo aqui é apenas ilustrar a transmissão dos choques valorizando o canal da dívida pública e os efeitos da sua composição. O estudo dos efeitos do policy mix será realizado em pesquisas futuras. Agradecemos a um referee anônimo por esse comentário.
} 
Tabela 6: Parâmetros da restrição orçamentária

\begin{tabular}{cclc}
\hline \multicolumn{2}{l}{ Médias no Período 1996:1-2007:2 } & \multicolumn{2}{c}{ Cálculo dos Parâmetros } \\
\hline $\bar{b}$ & 540,098 & $\psi_{0}$ & 0,0239 \\
$\bar{d}$ & $-12,911$ & $\psi_{1}$ & 0,0376 \\
$\bar{r}$ & 0,0380 & $\psi_{2}$ & 0,0177 \\
$\bar{\pi}$ & 0,01166 & $\psi_{3}$ & 1,0239 \\
$R^{*}$ & 0,0466 & $\phi$ & 0,5 \\
\hline
\end{tabular}

${ }^{*}$ Equivale a uma taxa de juros de $20 \%$ ao ano que é a média do período 2000:1 a 2007:6 da LTN de 12 meses, conforme IPEADATA.

A dinâmica do modelo sugere que podem existir efeitos que diminuem a eficácia da política monetária. Em um contexto de excesso de demanda e inflação, a política monetária reage de forma positiva, mas gera alguma aceleração da dívida pública o que estimula a demanda gerando um efeito contraproducente. Para o modelo convergir é importante que o efeito da dívida pública sobre a demanda agregada seja pequeno e/ou que o efeito da taxa de juros sobre a dívida seja pequeno. ${ }^{22}$

\subsection{Um Estudo em Pequenas Amostras e a Robustez do Canal a Dívida}

As evidências econométricas apresentadas nas Tabelas 4 e 5 devem ser analisadas com cuidado. A inferência estatística na presença de pequenas amostras apresenta distorções potencialmente sérias. Um procedimento que é muito utilizado para lidar com os problemas de inferência causados por pequenas amostras é o bootstrap. Esse procedimento consiste em basear a inferência estatística em distribuições que são calculadas por simulações ao invés da distribuição sugerida pela teoria assintótica que é válida apenas quando o tamanho da amostra é suficientemente grande. A preocupação com a inferência estatística justifica-se porque o modelo propõe um canal adicional de transmissão que deve ser suficientemente testado.

Com esse intuito, é conduzido um experimento de bootstrap baseado em Cho \& Moreno (2006). Tal procedimento consiste na estimação de um sistema de equações (FIML, por exemplo) e, em seguida, na resolução desse sistema em sua forma reduzida (VAR) na forma:

$$
X_{t}=c+\Omega X_{t-1}+\Gamma \varepsilon_{t}
$$

Para definir a hipótese nula estima-se um modelo VAR irrestrito dado por:

$$
X_{t}=d+\Theta X_{t-1}+v_{t}
$$

onde $\operatorname{Var}\left(\Gamma \varepsilon_{t}\right)=\Gamma D \Gamma^{\prime}$ e $\operatorname{Var}\left(v_{t}\right)=\Lambda$. O procedimento consiste em adotar a hipótese nula de que $\Gamma D \Gamma^{\prime}=\Lambda$. Vale notar que o erro do VAR irrestrito é ortogonalizado, utilizando-se Cholesky. Dessa forma, $\operatorname{Var}\left(v_{t}\right)=\Lambda=C C^{\prime}$, onde $C$ é uma matriz triangular inferior. Assim, pode-se escrever $v_{t}=C \xi_{t}$ onde $\xi_{t} \sim(0,1)$ e $\operatorname{cov}\left(\xi_{i}, \xi_{j}\right)=0$ para $i \neq j$ de forma que:

\footnotetext{
${ }^{22}$ Desde que o modelo foi estimado e os parâmetros da restrição orçamentária são perfeitamente identificados espera-se que não existam problemas de convergência do modelo, dada a estabilidade econômica observada na economia brasileira, principalmente após o ano de 2002 .
} 


$$
X_{t}=d+\Theta X_{t-1}+C \xi_{t}
$$

O modelo estrutural pode, então, ser escrito como:

$$
X_{t}=c+\Omega X_{t-1}+\Gamma \sqrt{D} \xi_{t}
$$

desde que $\varepsilon_{t}=\sqrt{D} \xi_{t}$.

$\mathrm{O}$ bootstrap sob a hipótese nula de que o modelo estrutural tem variância igual ao modelo irrestrito é feito pelas seguintes etapas:

i. É feito um sorteio dos erros irrestritos, $v_{t}$, com reposição formando um conjunto de tamanho $n$.

ii. São construídas $k$ amostras de $n$ conjuntos de dados sob a hipótese nula assumindo os parâmetros calculados em (13) e os valores iniciais da amostra original usando o distúrbio $\xi_{t}$ o qual é obtido utilizando-se o conjunto de dados montado na primeira etapa, pré-multiplicado por $C^{-1}$.

iii. É importante que $n$ seja grande para retirar a influência dos valores iniciais na geração dos dados que deve ter o mesmo tamanho da amostra real.

iv. O modelo é estimado $k$ vezes e são obtidos os $k$ parâmetros e as $k$ estatísticas de teste.

Pode-se obter, com os $k$ parâmetros, uma estimativa pontual a partir da média dos mesmos. Além disso, o intervalo de confiança obtido via bootstrap pode ser calculado como:

$$
\left[\Pi-\Phi t_{1-\alpha}, \Pi+\Phi t_{1-\alpha}\right]
$$

onde $\Pi$ é o vetor de parâmetros estimados por FIML inicialmente, $\Phi$ é o erro padrão dos respectivos coeficientes e $t_{1-\alpha}$ é a estatística de teste do bootstrap em que $\alpha$ representa a significância que se deseja obter.

O p-valor é calculado a partir do número de vezes que a estatística obtida pelo bootstrap excede a estatística obtida pelos dados originais o que pode ser escrito como:

$$
p *(t)=\frac{1}{B} \sum_{j=1}^{B} I\left(t_{j}>t\right)
$$

onde $B$ é o número de replicações do bootstrap, I é a função indicadora que toma valor igual a 1 quando a estatística $(t j *)$ for maior que a estatística estimada pelos dados originais $(t)$ e zero caso contrário.

Em relação ao procedimento de Cho \& Moreno (2006), cumpre notar que os autores utilizam um sistema de três variáveis e três equações, ou seja, todas as variáveis são endógenas. $\mathrm{O}$ arcabouço apresentado neste artigo difere um pouco porque o modelo contém duas variáveis endógenas e duas exógenas. Conforme MacKinnon (2002), o problema então passa a ser gerar as variáveis endógenas referentes ao modelo de equações simultâneas.

As alterações que adaptam o procedimento devem ser feitas na etapa inicial que consiste na resolução do modelo estrutural estimado por FIML no 
Tabela 7: Cálculo do P-valor no Bootstrap

\begin{tabular}{crccc}
\hline & Estatística & Percentil 0,025 & Percentil 0,975 & P-Valor \\
\hline & 4,5457 & $-1,30086$ & 2,16765 & 0,0010 \\
$\hat{r}_{t-1}$ & $-3,3692$ & $-6,54731$ & $-1,84446$ & 0,4265 \\
$\hat{b}_{t+1}$ & 2,3736 & $-0,62681$ & 2,91894 & 0,0779 \\
$\pi_{t-1}$ & 6,3284 & 4,01018 & 12,1961 & 0,6893 \\
$\hat{y}_{t}$ & 1,8710 & $-0,94117$ & 1,75520 & 0,0199 \\
\hline
\end{tabular}

Nota: A coluna 2 (Estatística) apresenta a estatística de teste obtida com os dados originais, a coluna 3 (percentil 0,025) corresponde ao percentil 2,5\% dos percentis obtidos por bootstrap, a coluna 4 (percentil 0,975 ) aos respectivos percentis de $97,5 \%$ e a coluna 5 (p-valor) ao p-valor definido como o número de bootstraps que excedem o d. p. estimado dividido pelo número total de replicações.

VAR. O método empregado pressupõe que a taxa de juros e a dívida pública são, de fato, exógenos o que se aproxima do modelo utilizado neste artigo. ${ }^{23}$ Nesse método, deve-se especificar o VAR irrestrito da mesma forma. Em outras palavras, o VAR irrestrito deve ser estimado tratando a dívida pública e a taxa de juros como exógenas a fim de se obter os resíduos.

A solução do modelo, em sua forma reduzida, é: ${ }^{24}$

$$
\begin{aligned}
& {\left[\begin{array}{l}
\hat{y}_{t} \\
\pi_{t}
\end{array}\right]=\left[\begin{array}{ll}
0 & 0 \\
0 & 1
\end{array}\right]\left[\begin{array}{l}
\hat{y}_{t-1} \\
\pi_{t-1}
\end{array}\right]+} \\
& {\left[\begin{array}{ll}
-0,025 & 0,128 \\
-0,012 & 0,063
\end{array}\right]\left[\begin{array}{l}
\hat{r}_{t} \\
\hat{b}_{t}
\end{array}\right]+\left[\begin{array}{ll}
1,000 & 0 \\
0,498 & 1,915
\end{array}\right]\left[\begin{array}{l}
\varepsilon_{A D} \\
\varepsilon_{A S}
\end{array}\right] }
\end{aligned}
$$

A aplicação do procedimento de bootstrap (etapas (i)-(iv)) sugere que o modelo possui algumas incongruências (Tabela 7). A primeira delas é que o parâmetro que mede o efeito da demanda agregada futura sobre a demanda agregada presente foi rejeitado no exercício de robustez. Nas 1.000 simulações nenhuma das estatísticas de teste superou a estatística de 4,54 obtida pelos dados originais de forma que o p-valor obtido foi 0,001 rejeitando, portanto a hipótese de que o verdadeiro parâmetro seja igual ao parâmetro estimado.

A segunda incongruência é o efeito da demanda agregada na curva de Phillips. Apenas $2 \%$ das estatísticas superaram o valor estimado de forma que podemos rejeitar o valor obtido ao nível de $5 \%$ mas não ao nível de $1 \%$. Os demais parâmetros não são rejeitados aos níveis usuais de confiança.

A comparação dos parâmetros estimados com a estimativa em bootstrap (Tabela 8) revela que o único parâmetro estimado em que a estimativa em bootstrap encontra-se fora do intervalo de confiança é o que mede o efeito da demanda futura sobre a demanda presente. Os demais parâmetros obtidos por bootstrap encontram-se dentro do intervalo de confiança. Nesse sentido, o efeito da dívida pública sobre a demanda agregada, que é a principal contribuição do modelo proposto, pode ser considerado robusto.

\footnotetext{
${ }^{23}$ Outro enfoque tentado pressupõe que a dívida pública também é endógena no VAR irrestrito e na resolução do modelo são impostas regras ad hoc de política monetária e fiscal e a restrição orçamentária o que se aproxima do enfoque utilizado por Cho \& Moreno (2006). Entretanto, não é exatamente igual porque as regras não são estimadas. Os resultados obtidos foram muito semelhantes aos reportados.

${ }^{24}$ Obtido na rotina dynare do matlab.
} 
Tabela 8: Intervalo de confiança dos parâmetro no Bootstrap

\begin{tabular}{ccccr}
\hline & Estimativa & Bootstrap & $\begin{array}{c}\text { Limite } \\
\text { Inferior }\end{array}$ & \multicolumn{1}{c}{$\begin{array}{c}\text { Limite } \\
\text { Superior }\end{array}$} \\
\hline & 0,522512 & 0,053677 & 0,273347 & 0,77167 \\
$\hat{r}_{t-1}$ & $-0,02455$ & $-0,02776$ & $-0,03799$ & $-0,01111$ \\
$\hat{b}_{t+1}$ & 0,127644 & 0,068108 & $-0,02933$ & 0,28461 \\
$\pi_{t-1}$ & 0,477433 & 0,464571 & $-0,44263$ & 1,39749 \\
$\hat{y}_{t}$ & 0,260291 & 0,218402 & 0,01606 & 0,50451 \\
\hline
\end{tabular}

Nota: A coluna 1 (estimativa) refere-se à estimativa dos dados originais, a coluna 2 (bootstrap) computa a média dos parâmetros estimados por bootstrap, a coluna 3 (limite inferior) corresponde ao limite inferior de $5 \%$ do intervalo de confiança dos parâmetros estimados e a coluna 4 (limite superior) apresenta o limite superior do mesmo.

\section{O Mecanismo de Transmissão das Políticas Monetária e Fiscal}

Como a inclusão do canal da dívida pública afeta a dinâmica desse modelo? Desde que os modelos tradicionais de curto prazo (novo keynesianos, por exemplo), em geral, não modelam a política fiscal é importante avaliar como esse canal de transmissão funciona.

Para avaliar a importância da inclusão do canal da dívida pública no modelo macroeconômico, são comparadas as funções impulso resposta do modelo estimado com as funções de impulso resposta de um modelo calibrado com o pequeno impacto da dívida pública na demanda agregada, aproximando, dessa forma, o modelo calibrado do modelo novo keynesiano com apenas três equações. O modelo calibrado usou como coeficiente da dívida pública na curva IS o valor $\alpha^{*}=0,05$ bem menor que o valor estimado que foi $\alpha=0,128$.

A Figura 1 apresenta as funções de impulso resposta dos dois modelos com o objetivo de comparar a dinâmica dos mesmos. No caso de choques de demanda os efeitos sobre a demanda agregada e sobre o déficit são equivalentes em ambos os casos. Desde que as funções impulso reposta mostram maior inércia da inflação e da taxa de juros no modelo calibrado, a dívida apresenta maior resposta no modelo calibrado que no modelo estimado.

No caso de choques de oferta, a dívida pública reage mais no modelo calibrado o que torna a demanda agregada e o déficit mais estável que no modelo estimado. Por outro lado, a taxa de inflação e a taxa de juros apresentam maior inércia no modelo calibrado que no modelo estimado.

No caso de choques fiscais, a dívida pública acelera mais no modelo calibrado que no modelo estimado enquanto que a demanda agregada e o déficit são mais estáveis no modelo calibrado. A taxa de juros e a taxa de inflação apresentam maior inércia no modelo calibrado que no modelo estimado.

Como conclusão geral, pode-se notar que com o canal da dívida pública operando, as funções de impulso resposta sugerem que o modelo converge para o equilíbrio de forma mais rápida que no modelo em que o canal da dívida pública não opera de forma plena (como é o caso do modelo calibrado). Esse resultado se dá porque a política monetária é mais eficiente no modelo estimado que no modelo calibrado porque o canal de transmissão é, por construção, maior. 

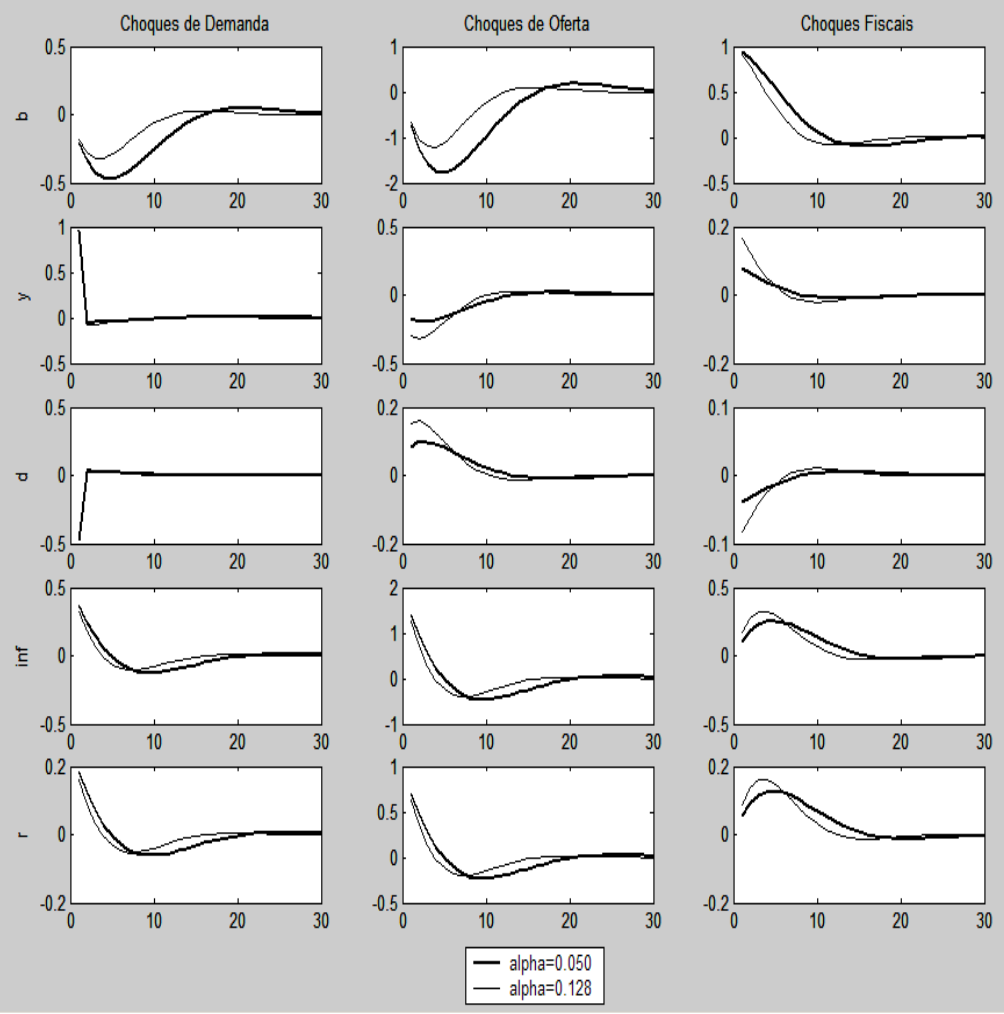

Figura 1: O Impacto da Dívida Pública no Canal de Transmissão da Política Monetária

Como a composição da dívida pública afeta a transmissão da política monetária? Para analisar o impacto dinâmico da gestão da dívida pública sobre a economia são simulados três modelos: o primeiro com a composição da dívida pública que se aproxima dos parâmetros observados para a economia brasileira $(\phi=0,5)$ e que foi o utilizado no exercício anterior. Os demais modelos simulam uma composição concentrada em títulos indexados à taxa de juros de curto prazo $(\phi=0,9)$ e uma composição concentrada em títulos prefixados $(\phi=0,1)$.

A Figura 2 apresenta as funções de impulso resposta com três composições para a dívida pública. Na ocorrência de choques de demanda, quanto mais prefixada for a dívida pública, maior a resposta da dívida e menor a inércia da taxa de inflação e da taxa de juros. Os efeitos sobre a demanda agregada e sobre o déficit não são distinguíveis.

$\mathrm{Na}$ presença de choques de oferta, quanto mais prefixada estiver a dívida pública, maior o efeito sobre a dívida pública, sobre a demanda agregada e sobre o déficit e menor o efeito sobre a taxa de inflação e a taxa de juros. Na presença de choques fiscais, quanto mais prefixada a dívida pública estiver, menor o impacto sobre a dívida, a taxa de inflação e a taxa de juros enquanto maior é a resposta da demanda agregada e do déficit.

Como conclusão geral pode-se notar que quanto maior a composição da dívida indexada à taxa de juros de curto prazo, maior a duração do ciclo econô- 

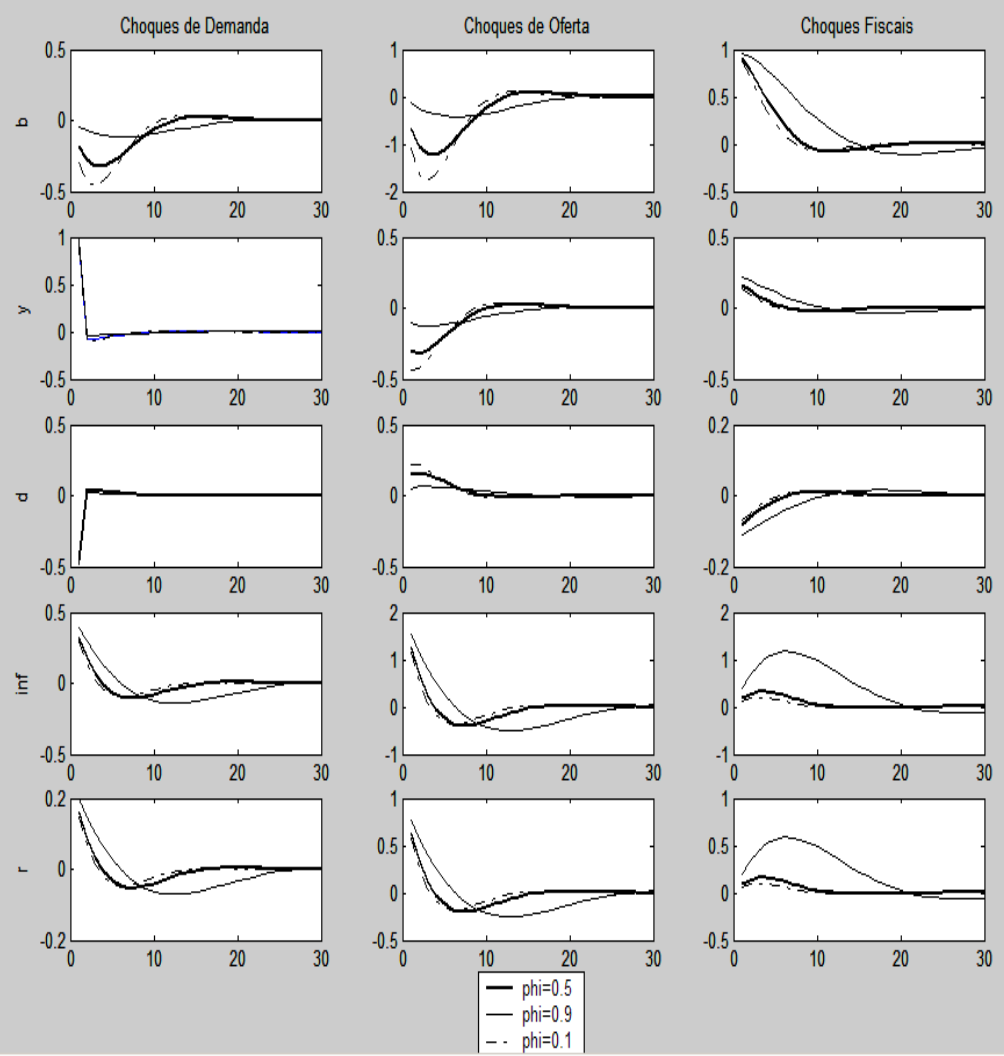

Figura 2: Efeitos da Composição da Dívida Pública

mico, ou seja, as variáveis levam mais tempo para convergir para os valores de equilíbrio.

\section{Conclusões}

Esse artigo teve por objetivo apresentar um modelo que incorporasse um papel para a dívida pública no canal de transmissão da política monetária. Com efeito, o modelo analisa os efeitos da dívida pública sobre a demanda agregada e da política monetária sobre a dinâmica da própria dívida pública. Ademais, o modelo incorpora o papel da gestão da dívida pública e suas implicações dinâmicas por meio da participação dos títulos indexados à taxa de juros de curto prazo o que adiciona um canal de transmissão para a política monetária.

A gestão da dívida pública pode ser sofisticada de várias formas. Em primeiro lugar, pode ser endogeneizada como função do déficit primário, pois quanto maior o déficit primário menor o poder de barganha do Tesouro Nacional na negociação dos títulos da dívida pública o que eleva a taxa de juros dos títulos, bem como prejudica sua composição, criando outro canal de transmissão para a política fiscal. Em segundo lugar, a composição da dívida pública pode ser obtida de forma ótima de acordo com as preferências dos agentes que desejam maximizar uma função utilidade, gerando uma demanda por títulos públicos, sendo a oferta determinada pelo déficit público. 
Uma agenda de pesquisa importante consiste na inclusão do setor externo nesse tipo de modelo. Isso permitirá explicitar o pass-through da taxa de câmbio para a inflação, o efeito da taxa de câmbio real sobre o nível de atividade e possibilitará a inclusão de títulos indexados à taxa de câmbio para avaliar os efeitos macroeconômicos da gestão da dívida pública.

Ainda que essas possibilidades sejam importantes, os fatos da economia brasileira discutidos nesse artigo sugerem que a composição da dívida pública não se modificará com velocidade suficiente para invalidar a análise realizada. Durante o período analisado, a participação dos títulos indexados à taxa de juros de curto prazo sempre foi maior que 50\% com exceção do ano de 2006. Esse lento processo de substituição de títulos indica que a aproximação realizada ao tratar a composição de forma exógena pode ser considerada um bom enfoque na discussão da transmissão da política monetária bem como os impactos da gestão da dívida pública na coordenação das políticas monetária e fiscal.

Os resultados indicam que a inclusão da dívida pública no canal de transmissão da política monetária faz com que, na presença de choques, as varáveis macroeconômicas convirjam de forma mais rápida para o steady state. Quando esse canal não opera plenamente, existe maior inércia nas variáveis macroeconômicas, fazendo com que choques se dissipem de forma mais lenta. Além disso, a composição da dívida pública também modifica a dinâmica do modelo. Com efeito, quanto maior a participação dos títulos indexados à taxa de juros de curto prazo, mais longa é a resposta das variáveis aos choques que atingem o modelo.

\section{Referências Bibliográficas}

Barro, R. (1974), 'Are government bonds net wealth?', Journal of Political Economy 82, 1095-1117.

Benigno, P. \& Woodford, M. (2006), Optimal inflation targeting under alternative fiscal regimes, Technical report, NBER.

Bevilaqua, A., Mesquita, M. \& Minella, A. (2007), Brazil: taming inflation expectations, Technical report, Banco Central do Brasil.

Blanchard, O. (1985), 'Debt, deficits and finite horizons', Journal of Political Economy 93, 223-2477.

Blanchard, O. \& Perrot, R. (2002), 'An empirical characterization of the dynamic effects of changes in government spending and taxes on output', The Quartely Journal of Economics 117, 1329-1368.

Blinder, A. (1982), Issues in the coordination of monetary and fiscal policy, in 'Monetary Policy Issues in the 1980's - A symposium sponsored by the Federal Reserve of Kansas City'.

Bénassy, J. P. (2007), Money, interest and policy: dynamic general equilibrium in a non-ricardian world, Technical report, MIT Press.

Cho, S. \& Moreno, A. (2006), 'A small-sample study of the new keynesian macro model', Journal of Money, Credit and Banking 38, 1461-1482. 
Favero, C. (2004), 'Comments on: Fiscal and monetary policy interactions: Empirical evidence on optimal policy using a structural new-keynesian model', Journal of Macroeconomics 26, 281-285.

Fraga, A., Goldfajn, I. \& Minella, A. (2003), 'Inflation targeting in emerging market economies', NBER Macroeconomics Annual 18, 365-400.

Guidotti, E. \& Kumer, M. (1991), Domestic public debt of externally indebted countries, Technical report, FMI occasional paper.

Kirsanova, T., Stehn, S. \& Vines, D. (2005), 'The interactions between fiscal policy and monetary policy', Oxford Review of Economic Policy 21, 532-564.

Lambertini, L. \& Rovelli, R. (2003), Monetary and fiscal policy coordination and macroeconomic stabilization: A theoretical analysis, Technical report, Universidade de Bolonha.

Leeper, E. (1991), 'Equilibria under 'active' and 'passive' monetary and fiscal policies', Journal of Monetary Economics 27, 129-147.

Loyo, E. (2006), Política monetária e alongamento da dívida pública, in 'Mercado de capitais e Dívida pública', Editora Contracapa.

MacKinnon, J. (2002), 'Bootstrap inference in econometrics', The Canadian Journal of Economics 35, 615-645.

Modigliani, F. \& Sutch, R. (1966), 'Innovations in interest rate policy', The American Economic Review 56, 178-197.

Mountford, A. \& Uhlig, H. (2002), What are the effects of fiscal policy shocks, Technical report, CEPR.

Muscatelli, V., Tirelli, P. \& Trecroci, C. (2004), 'Fiscal and monetary policy interactions: Empirical evidence and optimal policy using a structural newkeynasian mode', Journal of Macroeconomics 26, 257-280.

Nordhaus, W. (1994), 'Policy games: Coordination and independence in monetary and fiscal policies', Brookings Papaers on Economic Activity 2, 139-216.

Pastore, A. C. (1995), 'Por que a política monetária perde eficácia?', Revista Brasileira de Economia 50, 281-311.

Peres, M. A. F. (2007), Os efeitos dinâmicos da política fiscal sobre a atividade econômica: Um estudo para o caso brasileiro, in 'XII Prêmio do Tesouro Nacional. Secretaria do Tesouro Nacional'.

Perrot, R. (2007), 'In search of the transmission mechanism of fiscal policy', NBER Macroeconomics Annual 22, 169-226.

Ramey, V. A. \& Shapiro, M. (1998), 'Costly capital reallocation and the effects of government spending', Carnegie-Rochester Conference Series on Public Policy 48, 145-194.

Saikkonen, P. \& Lutkepohl, H. (2002), 'Testing for a unit root in a time series with a level shift at unknown time', Econometric Theory 18, 313-348. 
Sargent, T. (1981), The end of four big inflations, Technical report, Fed Minneapolis.

Tobin, J. (1963), An essay on the principles of debt management., in 'Fiscal and Debt Management Policies, Comission on Money and Credit.', Cowles Foundation Paper.

Tobin, J. (1980), Asset accumulation and economic activity: Reflections on contemporary macroeconomic theory, The University of Chicago Press.

Woodford, M. (2003), Interest and prices: Foundations of a theory of monetary policy, Princeton University Press.

\section{Apêndice A}

\section{A.1 Derivação da Restrição Orçamentária do Governo}

A equação (13) pode ser escrita da seguinte forma:

$$
b_{t}-d_{t}=\left[\phi\left(1+r_{t}\right)+(1-\phi) \frac{(1+R)}{\left(1+\pi_{t}\right)}\right] b_{t-1}
$$

Aplicando log em ambos os lados:

$$
\log \left(b_{t}-d_{t}\right)=\log \left[\phi\left(1+r_{t}\right)+(1-\phi) \frac{(1+R)}{\left(1+\pi_{t}\right)}\right]+\log \left(b_{t-1}\right)
$$

A regra utilizada para a loglinearização foi:

$$
\log f\left(X_{t}, Y_{t}\right)=\log f(X, Y)+\frac{1}{f(X, Y)}\left(f_{1}(X, Y) X x_{t}+f_{2}(X, Y) Y y_{t}\right)+\varepsilon_{t}
$$

Onde $f_{1}$ é a derivada com relação ao primeiro argumento da função e assim por diante e $\hat{x}_{t}=\log x_{t}-\log \bar{x}$ em que $\hat{x}$ é o valor de equilíbrio de steady state.

Aplicando a regra postulada acima, obtém-se para o termo da esquerda:

$$
\log \left(b_{t}-d_{t}\right)=\log (\hat{b}-\bar{d})+\frac{1}{\bar{b}-\bar{d}}\left(\hat{b}\left(\hat{b}_{t}\right)-\hat{d}\left(\hat{d}_{t}\right)\right)+\varepsilon_{t}
$$

Aplicando a regra para o primeiro termo da direita, obtém-se:

$$
\begin{aligned}
\log \left[\phi\left(1+r_{t}\right)+\right. & \left.(1-\phi) \frac{(1+R)}{\left(1+\pi_{t}\right)}\right]=\log \left[\phi(1+\bar{r})+(1-\phi) \frac{(1+R)}{(1+\bar{\pi})}\right] \\
& +\frac{1}{\phi(1+\bar{r})+(1-\phi) \frac{(1+R)}{(1+\bar{\pi})}}\left(\phi \bar{r}\left(\hat{r}_{t}\right)-(1-\phi) \frac{(1+R)}{(1+\bar{\pi})^{2}} \bar{\pi}\left(\hat{\pi}_{t}\right)\right)+\varepsilon_{t}
\end{aligned}
$$

Aplicando a regra para o segundo termo da direita, obtém-se:

$$
\log \left(b_{t-1}\right)=\log \bar{b}+\frac{1}{\bar{b}} \bar{b}\left(\hat{b}_{t-1}\right)+\varepsilon_{t}
$$

Ao igualar os valores de equilíbrio: 


$$
\log (\bar{b}-\bar{d})=\log \left[\phi(1+\bar{r})+(1-\phi) \frac{(1+R)}{\left(1+\bar{\pi}_{t}\right)}\right]+\log (\bar{b})
$$

Usando a definição acima, os valores de equilíbrio podem ser eliminados e a seguinte relação é obtida:

$$
\begin{gathered}
{\left[\frac{\bar{b}}{\bar{b}-\bar{d}}\right] \hat{b}_{t}=\left[\frac{\bar{d}}{\bar{b}-\bar{d}}\right](\hat{d})_{t}+\hat{b}_{t-1}} \\
+\frac{1}{\phi(1+\bar{r})+(1-\phi) \frac{(1+R)}{(1+\bar{\pi})}}\left[\phi \bar{r} \hat{r}_{t}-(1-\phi) \frac{(1+R)}{(1+\bar{\pi})^{2}} \bar{\pi} \hat{\pi}_{t}\right]+\varepsilon_{t} \\
\psi_{0}=\frac{\bar{d}}{\bar{b}} ; \psi_{1}=\frac{(\bar{b}-\bar{d}) \bar{r}}{\bar{b}\left\{\phi(1+\bar{r})+(1-\phi) \frac{\left(1+R^{*}\right)}{(1+\bar{\pi})}\right\}} ; \\
\psi_{2}=\frac{(\bar{b}-\bar{d}) \bar{\pi}\left(1+R^{*}\right)(1+\bar{\pi})^{-2}}{\bar{b}\left\{\phi(1+\bar{r})+(1-\phi) \frac{\left(1+R^{*}\right)}{(1+\bar{\pi})}\right\}} ; \psi_{3}=\frac{\bar{b}-\bar{d}}{\bar{b}} .
\end{gathered}
$$

onde os quatro parâmetros são assumidos maiores que zero como caso relevante $(\bar{b}>\bar{d})$. 


\section{Apêndice B Evolução das variáveis}
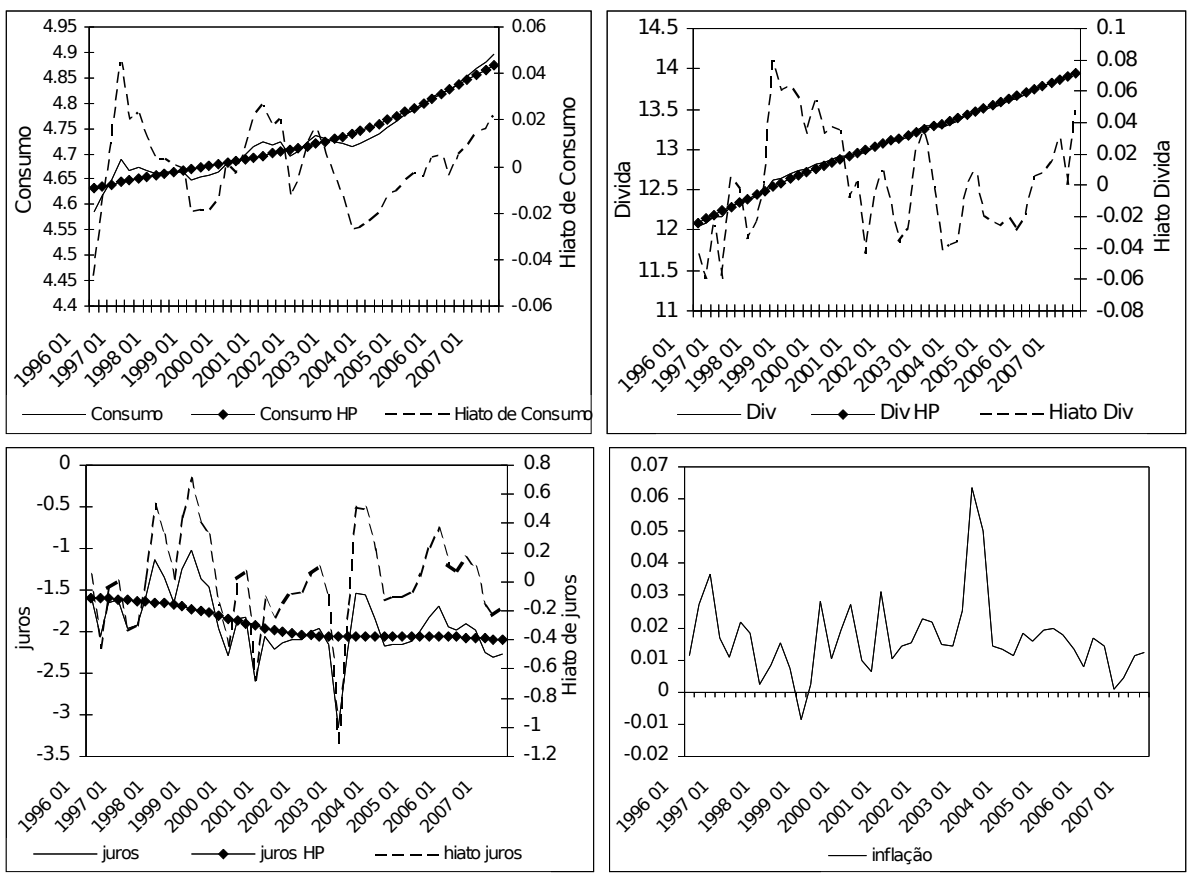

Figura B.1: Evolução das Variáveis

Tabela B.1: Valores no Estado Estacionário

\begin{tabular}{cc}
\hline Variáveis & Estado Estacionário \\
\hline$\hat{c}_{t}$ & 0,000 \\
$\hat{b}_{t}$ & 0,000 \\
$\hat{r}_{t}$ & 0,000 \\
$\hat{d}_{t}$ & 0,000 \\
$\pi_{t}$ & 0,016 \\
\hline
\end{tabular}

